\title{
Integrating Culture and Biology in Psychological Research: Conceptual Clarifications and Recommendations
}

\author{
Moin Syed and Ummul-Kiram Kathawalla \\ University of Minnesota
}

$08 / 2016$

To appear in:

In J. M. Causadias, E. H. Telzer, \& N. A. Gonzales (Eds.), Handbook of culture and biology interplay: Bridging evolutionary adaptation and development. New York: Wiley.

Address correspondence to Moin Syed, moin@umn.edu

\begin{abstract}
The increased prevalence of psychological research that integrates cultural and biological perspectives requires that we take stock of how the field approaches important issues of conceptualization and measurement. The primary goal of this chapter is to raise some substantial conceptual and methodological issues of which researchers in the field should be aware. To this end, the chapter includes an in-depth discussion of the nature of cultural psychology, highlights the need to carefully conceptualize the nature of cultural groups, and addresses the ongoing debate about the biological basis of race. The second half of the chapter provides some specific recommendations for future researchers who wish to pursue a rigorous scientific approach to understanding the interplay of culture and biology.

Keywords: Culture, Biology, Methodology, Ethnicity, Race, Theory
\end{abstract}


Psychological research that integrates cultural and biological perspectives has become increasingly prevalent in the last decade (see reviews by Causadias, 2013; Han et al., 2013; Kim \& Sasaki, 2014; Mrazek, Harada, \& Chiao, 2015). Despite the apparent impressiveness of the scope and methods of this work, psychological research integrating cultural and biological processes remains very much in its infancy. This fledgling status leads to great excitement about the new questions that can be asked and answered; very little has been addressed empirically, and thus the sky is seemingly the limit for the future of the field. At the same time, its nascence demands that we take stock of how the field approaches conceptualization and measurement, before we get too deep, too rooted in one way of doing things.

The purpose of this chapter is to provide such a reflection. The primary goal of our chapter is to raise what we view as some of the most substantial conceptual and methodological issues of which researchers in the field should be aware. This chapter is by no means intended to serve as an exhaustive review of the field, nor is it intended to address all critical issues in this area of research. Rather, it is meant to provide a broad introduction to the types of thinking that we feel researchers interested in culture and biology interplay would benefit from engaging.

To facilitate our goals, the chapter is organized into two broad sections. In the first section we address the question, what is cultural psychology? Within this discussion we highlight the critical need for researchers studying culture and biology to carefully conceptualize the nature of cultural groups, and pay special attention to the supposed biological basis of race. We adopt a broad view of culture that involves shared meanings, values, and practices within and among groups (Cohen, 2009; Rogoff, 2003; Shweder, 2000). We do not offer a companion section on what is biological psychology? The conceptualization of biological psychology is not nearly as diffuse and contested as is cultural psychology. Biological psychology generally refers to linking genetics or activities of the nervous system to behavior and mental process. Numerous specific approaches are subsumed under this broad header, including behavior genetics, cognitive/affective/social neuroscience, and physiological psychology. We do not treat these separately in this chapter, as the issues we raise are broadly applicable across different levels of analysis. It is also important to note that, although we use the phrasing "culture and biology" throughout this chapter, and often discuss them as independent levels of analysis, we do so with full recognition that the two are not so easily separable.

In the second broad section of this chapter we provide some specific recommendations for future researchers who wish to pursue a rigorous scientific approach to understanding the interplay of culture and biology. The ultimate goal with this chapter is to encourage researchers to engage in deeper thinking about conceptual and methodological issues that have the potential to compromise their work.

\section{What is Cultural Psychology?}

The term "cultural psychology" refers to a broad family of approaches dedicated to understanding human diversity in psychological processes. Understanding that cultural 
psychology is broad, subsuming many different approaches, is critical in the context of this chapter, as there may be different concerns associated with each of the different cultural approaches.

Shweder (2000) articulated the nature and relations of the "three psychologies": cultural psychology, cross-cultural psychology, and indigenous psychology. Each of these represents an approach to conducting research on the cultural nature of behavior and mental processes. Cultural psychology assumes psychological pluralism; that cultures and societies around the world exhibit different mentalities that define their psychological experience (see also Hammack, 2008; Rogoff, 2003). The emphasis of cultural psychology tends to be on the meanings that people make of their existence, from their own perspective. Importantly, cultural psychology does not reject the idea that there are universal or common processes among groups of people. Indeed, most cultural psychologists subscribe to the idea that while general psychological processes might be universal (e.g., developing a sense of identity), the specific instantiations of those processes (e.g., the content of the identity) will vary by culture. Indigenous psychology, according to Shweder (2000), is more or less the same as cultural psychology in its emphasis on local psychological meanings. However, indigenous psychology often originates from within the culture that is being studied (vs. an outside researcher studying a different cultural community), makes greater use of culture-specific folk concepts, and may be less concerned than cultural psychology for the implications of the findings outside of the context in which they were generated. In contrast, cross-cultural psychology is largely an extension of "mainstream" or non-cultural psychological research (Segall, Lonner, \& Berry, 1998). Cross-cultural psychologists are generally more concerned with establishing human universals in psychological processes and contents, and thus are oriented towards testing the generalizability of existing findings or establishing cross-cultural measurement invariance of established constructs (Matsumoto, 2003). This orientation towards generalization is a very different focus from that of cultural psychology and its focus on local meanings that may or may not generalize.

Shweder's (2000) description of these three psychologies is clear and important, yet also incomplete in two primary ways. First, his analysis does not fully articulate the diversity of approaches within the cultural psychology framework. There are three general approaches we will expand on here. First, there is the cultural-developmental work falling under the umbrella of sociocultural theory, which is largely based on the writings of Vygotsky (1978), Leont'ev (1978). This approach places a strong emphasis on development as culturally situated and mediated through tool usage (e.g., language and communication), and thus frequently consists of analyses of psychological phenomena embedded in activities (Rogoff, 2003). A somewhat similar approach, most clearly linked to the cognitive approach of Bruner (1990), Harré (2015), and others, focuses heavily on culture as meaning, as discussed by Shweder (2000), but places greater emphasis on meaning constructions in naturally occurring conversations. This discursive approach to psychology takes a stronger stance on power dynamics than sociocultural theory, seeking to understand how contexts can constrain cultural expressions (Durrheim \& Dixon, 2010). Finally, a third approach to cultural psychology, found mostly in social psychology, may be most recognizable to readers. This work is strongly based in Hofstede's (1980) cultural 
dimension of individualistic vs. collectivistic values and Markus and Kitayama's (1991) corresponding theory of independent vs. interdependent self-construals. This very large body of research is a good example of comparative cultural psychology (see handbook by Kitayama \& Cohen, 2010); that is, although group comparisons are foundational to this approach, the goal is not generalization of psychological processes across cultures. In fact, the goal is often the opposite: to demonstrate that cultures are quite different in some fundamental psychological process (what they value, how they understand the self), and that these differences have major ramifications for how people think about and behave in the world. Thus, cultural psychology itself, even within Shweder's (2000) restricted definition, is quite diverse.

In a related vein, the second aspect lacking in Shweder's (2000) presentation is the absence of ethnic minority psychology (Cauce, Coronado, \& Watson, 1998). Ethnic minority psychology is concerned with the psychological experiences of ethnic minorities within a specific nation, and can focuses on a single ethnic group or examine the similarities and differences among various ethnic groups (Cauce et al., 1998). The critical component of ethnic minority psychology is the focus on the minority. Ethnic minority research is always situated within the context of power differentials and access to societal resources, and seeks to understand individuals' psychological experiences by examining the barriers minorities face and the strengths they draw upon to overcome them (García Coll et al., 1996; Cooper, 2011). This is clearly a different project than cultural or cross-cultural psychology, as defined by Shweder (2000). Due to the ethnic diversity in the United States and Canada, the vast majority of ethnic minority research is conducted in these two countries, although significant research also comes out of the Netherlands (Verkuyten, 2005), the United Kingdom (Gaines et al. 2010), Sweden (Gyberg, Syed, Frisén, Wängqvist \& Svensson, 2016) and Israel (Seginer \& Mahajna, 2004), among many other countries.

Taken together, when thinking about research on culture and biology, there are many different broad approaches to culture in which the investigation may be situated. It is important to be aware of these different approaches and to be explicit about which one guides the study. Existing research on culture and biology is not evenly distributed across these different forms, with relatively greater prevalence within the social psychological approach to cross-cultural psychology (e.g., Chiao \& Blizinsky, 2010) and essentially none within the culture as meaning approach. Moreover, given the historical factors and power dynamics, research on culture and biology may be received differently within these different approaches, both by researchers and the communities they study. For example, studying genetic factors underlying mental health among African Americans may call for different conceptualizations and safeguards then when studying the same topic among White Americans (see Snowden, 2012). The need to think about how research might be differentially executed with different groups raises the vexing issue of how to conceptualize groups, an issue to which we now turn.

\section{On terminology used in cultural psychology}

The need to think about how to conceptualize groups may be one of the most pressing issues for the future of culture and biology research. Moreover, as we will discuss, 
taking seriously the nature of group definition poses a major threat to the interpretation of past research, as well as the ability for it to serve as the necessary cumulative foundation. Conceptualization of groups is critical to culture and biology because groups represent the starting point in any conceptual model: Whether a study is focused on one specific group or comparing multiple groups, some boundaries for inclusion or exclusion from each group have been set a priori. What processes do researchers use to set these boundary conditions? What criteria are used to determine the nature of the group definition?

The answer to these questions is, essentially, none. Rather than using specific processes or criteria, the vast majority of research in culture and biology relies on colloquial understandings of groups, many of which are potentially misleading. To be fair, this is by no means a problem that is limited to the domain of culture and biology. The challenge in defining and conceptualizing groups has a long history in psychology that continues to this day (Anastasi, 1937; García Coll, Akerman, \& Cicchetti, 2000; Gjerde, 2004).

The terms race, ethnicity, culture, and nation are difficult to define. Each has a separate meaning, although there is ongoing debate about what those meanings are. Moreover, there is considerable overlap among the terms, rendering it nearly impossible to conceptualize them as orthogonal. Nevertheless, any inquiry situated within the phenomena captured by these terms should be clear as to the meaning that will be used. We briefly do that here.

The terms race and ethnicity may have the most contentious definition and may be the most difficult to disentangle. Despite this, there is growing consensus among social scientists about how to best understand and use these terms (see Umaña-Taylor et al., 2014). Race is considered a socially constructed system of power and dominance. Although debate continues, most researchers agree that there is little evidence of a biological basis for race (more on this issue below). Thus, rather than considered a characteristic of the individual, race is conceptualized as a system of power that confers dominance upon the majority and marginalization upon the minority.

Ethnicity is also a historically and socially informed construct but tends to have a closer conceptual connection to culture than does race (Syed \& Mitchell, 2013). Ethnicity generally corresponds to the history, beliefs, and practices of a relatively homogenous group. If this definition sounds similar to what a definition of culture might look like, that's because it is. There are, however, important distinctions between the two. Culture is a system of shared beliefs, practices, and ways of living. Ethnic groups share a cultural background, but cultural groups may or may not share an ethnic background (e.g., American culture comprises many ethnic groups). In this way, culture can be thought of as a broader, higher order construct that encompasses ethnicity.

Nations can encompass many races, ethnicities, and cultures, and thus may be the least specific of the terms. Some nations may comprise highly diverse race, ethnicities, and cultures, particularly in the context of colonialism and imperial nation-building (e.g., Iraq) and large-scale immigration (e.g., United States). Nation does, of course, have meaning, but 
it does not often have the meaning that many believe it does in psychological research; that is, nation is not the same thing as culture (see Matsumoto, 1999). There can be a "national culture" that has psychological relevance, but it must be understood that the national culture overlies many distinct cultures that may or may not resemble the national one (McLean \& Syed, in press). For this reason, cross-national studies are often difficult to interpret because it is unclear which culture is represented in the data.

To put the different definitions in the simplest possible terms, race pertains to social groups formed within a system of power, ethnicity pertains to social groups who share a cultural background, culture itself is a system of beliefs, practices, and behaviors, and nation refers to the country in which individuals live. Shared characteristics contribute to ongoing deliberations about the distinctiveness of the terms within psychological research (Cokley, 2007; Helms et al., 2005). Moreover, race and ethnicity can be particularly difficult to separate in the context of actual research practice. For this reason, many have adopted a hybrid term race/ethnicity to acknowledge that the terms are distinct and that it is not really possible to separate race and ethnicity (Syed \& Mitchell, 2013; Umaña-Taylor et al., 2014).

\section{On the supposed biological basis of race and the justified skepticism of culture and biology research}

There are many reasons for cultural psychologists to be concerned, and even skeptical, about the increasing integration of biological factors in cultural research. Indeed, there is a long history of biological arguments being used to advance racial superiority (Graves, 2001). In-depth analyses of biological theories of race through history are available elsewhere, and the interested reader is encouraged to consult those texts (e.g., Graves, 2001; Smedley \& Smedley, 2005). The genetic basis of intelligence is the substantive domain that has certainly been the focus of the most controversy and scholarly dispute, and thus serves as a good example. To be clear, there is certainly strong evidence for the heritability of intelligence, indicating a clear genetic contribution (Neisser et al., 1996). At the same time, there is strong evidence for environmental contributions to intelligence (e.g., Turkheimer, Haley, Waldron, D’Onofrio, \& Gottesman, 2003). The genetic basis of intelligence is an unsurprisingly sensitive topic for many, given that race and racial differences have been at the center of the discussion. From the eugenics movement in the late 1800 s and early 1900s, to Rushton's research on race, brain size, and intelligence (Rushton \& Jensen, 2005; but see Cain \& Vanderwolf, 1990), to the publication of the The Bell Curve (Herrnstein \& Murray, 1994), genetics, race, and intelligence has been the subject of academic and popular debate.

A central question vis-à-vis the context of this chapter is the nature of the groups being compared. A brief snapshot of American history highlights the tenuous and shifting nature of race. Around the turn of the $20^{\text {th }}$ century, European immigrants from Irish, Italian, and Jewish backgrounds were not considered White, but of a different "race" of their own (Hochschild, 2005). Over time, with the changing economic and immigrant contexts, these groups have been absorbed into the broader White "racial" group, although vestiges of their recent minority status remain (Lipsitz, 1998). More recently, in the wake 
of the September $11^{\text {th }}$ attacks on the U.S., Muslims have become racialized. That is, a single historical event created a racial group from a highly diverse group of approximately 1.6 billion people as of 2010 who live all around the world (Lipka, 2015). The process is best described as racialization because a power structure has been enacted in the U.S. and other countries around the world that enables racial profiling, hate crimes, and restrictions on religious freedoms (Meer \& Modood, 2009). Latinos in the U.S. also present a curious case. According to the federal government, Latinos (or Hispanics ${ }^{1}$ ) are not a race but an ethnicity (Humes, Jones, \& Ramirez, 2010). However, Latinos have also been racialized, particularly in the context of immigration and bilingual education (Solis, 2003). This historical dynamism of race makes it difficult to derive a single definition, and is one of the arguments for a social constructivist vs. biological view on race (Helms, Jernigan, \& Mascher, 2005).

The belief in racial taxonomies as "natural" is evident all around in psychological research. In response to the media's discussion and portrayal of The Bell Curve, a group of 52 researchers contributed to a Wall Street Journal Editorial, "Mainstream Science on Intelligence" (see Gottfredson, 1997 for the editorial and some background). The statement consisted of 25 brief points that cover general issues of what intelligence is, how it can be measured, its genetic basis, and racial variation. On this latter issue, point \#7 reads, in part, "Members of all racial-ethnic groups can be found at every IQ level....but groups often differ in where their members tend to cluster along the IQ line" (Gottfredson, 1997, pp. 14). Based on this statement, they took as fact that the particular racial groups identified could be reliably and meaningfully classified. It is not until point \#24 that they write, "Because research on intelligence relies on self-classification into distinct racial categories,...its findings likewise relate to some unclear mixture of social and biological distinctions among groups (no one claims otherwise)" (Gottfredson, 1997, pp. 15). Thus, appropriately, they cast doubt on the accuracy and meaningfulness of the categories; the same categories that, in several earlier points in the list, they made references to in regards to reliable and valid group differences in intelligence. Rather than coming at the end of the list, it would have been more appropriate to begin with the problems of racial categorization and highlight how such problems render all subsequent points regarding race as tenuous. Indeed, there is currently great consensus across numerous disciplines that the evidence for a biological basis of race is severely lacking (Bonham, Warshauer-Baker \& Collins, 2005; Caufield et al., 2009; Teo, 2009; but see Risch, Burchard, Ziv, \& Tang, 2002). Indeed, there is agreement that any racial variations in genetic patterns can be attributed to geographic regional origins, and not race (e.g., sickle-cell anemia, often considered a "Black disease" is an adaptive genetic mutation found in malaria-prevalent areas, including India, the Caribbean, and sub-Sahara Africa; Rees, Williams, \& Gladwin, 2010; Serre \& Pääbo, 2004).

\footnotetext{
${ }^{1}$ The term "Hispanic" itself is an interesting case story in race. The term was popularized by Richard Nixon's administration as a way to classify a group of diverse people for social and political purposes. Because of this, and because of the link to their Spanish colonizers, many prefer the term Latino, which is what we use in this paper. However, there is wide geographical variation in what is considered an acceptable term, with Hispanic being much more acceptable on the U.S. East Coast than the West Coast.
} 
A great deal of ink has been devoted to discussing the challenges and perils of racial classification and the definition of groups (Bhopal, 2003; Gjerde, 2004; Hochschild, 2005). One way to think about all of this is that a supposed, but incorrect, biological model of groups serves as the foundation for how we think about groups. We then examine how these groups differ in biological functions. However, this tautological approach rests on a false premise. Indeed, there is great irony to lauding the rigorous "scientific" approach to their research when they take racial groups as givens, not seriously questioning the origins of how the groups were constructed (see Lipsitz, 1998 for a fascinating account of the creation of "Whites" in the U.S., and Teo, 2009, on the origins and problems of the term "Caucasian"). The following section of this chapter provides some suggestions for what a scientific study of culture and biology ought to be.

\section{The Path Forward: Recommendations for a Sensible Science of Culture and Biology}

Despite the emphasis heretofore on questions and criticisms associated with culture and biology research, the integration of these two broad levels of analysis is important for the future of psychology. Indeed, there are many exciting programs of research that have struck a proper balance between innovation and rigor (e.g., Neblett \& Roberts, 2013; Obasi et al., 2015), and building upon these exemplars will be important in developing a credible knowledge base. In this final section, we provide recommendations and considerations for scholars engaging in culture and biology research.

\section{Assess the psychological process underlying group differences}

It is essential that studies conceptualize, measure, and analyze the psychological processes that underlie any purported group-based phenomenon. This is especially important for cultural comparative work, in which two or more cultural groups are compared on some process. At this point in our knowledge of cultural processes, methodologies, and interpretive pitfalls, there is little justifiable reason to compare groups analytically and leave interpretation up to speculation. For example, if "Asians" and "Westerners" are compared on some outcome, interpretation will often rely on differences in interdependent versus independent self-construals, respectively (see Matsumoto, 1999). That people from such cultural groups align with these self-construals, however, is a point of serious contention in the literature (Matsumoto, 1999; Gjerde, 2004; Oyserman, Coon, \& Kemmelmeier, 2002; Syed \& Mitchell, 2013; Takano \& Osaka, 1999). Illustrating this approach, Kitayama and colleagues (2015) compared the association between expressions of anger and biological health risk (a composite of four inflammation and cardiovascular malfunction biomarkers) among a sample of Japanese and American adults. They purported to assess how "culture" moderated the association between expressions of anger and biological health risk, but they did not actually include any measure of culture. Rather, they used national origin of the participants as a proxy for culture, and then interpreted the findings in the context of cultural differences in independent and interdependent selfconstruals (which were not assessed in the study). Again, this analytic approach has been roundly criticized for what should be obvious reasons (Gjerde, 2004; Matsumoto, 1999; Tamis-Lemonda et al., 2008). 
Rather than relying on contested cultural stereotypes, the putative psychological mechanism underlying group differences must be tested (Helms et al., 2005). Doing so may lead to surprises. Chiao and colleagues (2009) conducted a study examining whether activations in the medial prefrontal cortex (MPFC) during a self-relevant judgment task was associated with participant ratings of individualism and collectivism among a sample of White Americans and Japanese. The primary finding was that MPFC activation was greater when participants identifying as individualistic described themselves in general terms and when participants identifying as collectivistic described themselves in contextual terms. The importance of actually assessing the cultural values is clear: Using a categorical procedure ${ }^{2}$, they found that the Japanese participants were more likely than Americans to be classified as individualistic (58\% vs. 25\%) and thus conversely the Americans were more likely than the Japanese to be classified as collectivistic (75\% vs. 42\%). Thus, consistent with past research (e.g., Takano \& Osaka, 1999), self-construal did not map on to national origin as is repeatedly asserted in the literature (e.g., Kitayama et al., 2015). Importantly, this study relied on a very small sample $(N=24)$, so any findings should either be held as tenuous or should be regarded with extreme skepticism. Indeed, as will be discussed next, there are many critical methodological issues that must be attended to in research on culture and biology.

\section{Clue in to the myriad discussions of methods reforms in the wake of the "reproducibility crisis"}

For the most part, cultural psychologists have been noticeably absent from the conversations about reforming the science of psychology (see John, Loewenstein, \& Prelec, 2012; Open Science Collaboration, 2015). This could be, in part, because many of the issues arose out of experimental social psychology, an approach used by only a small slice of cultural psychologists. Researchers in biological psychology, in contrast, have been very involved in the debate, particularly those in behavior and molecular genetics and social cognitive neuroscience. It is worth considering these areas in some detail.

Much of the existing research on cultural genetics takes a candidate gene approach, often in the context of a genetic x environmental (GxE) design (Beach, Brody, Lei, Kim, \& Cui, 2014; Obasi et al., 2015; see Kim \& Sasaki, 2014, for a review). GxE models examine how the association between an environmental factor and aiven outcome depends on the presence of particular genetic polymorphism (Duncan, Pollastri, \& Smoller, 2014). Arguably the most well-known of these types of analyses is Caspi and colleagues' (2003) study of stressful life events and depression, in which they found that the presence of the short allele on the 5-HTT serotonin transporter resulted in a stronger association between stress and depression. In other words, the genetic polymorphism moderated the association between stress and depression, providing clues about why some people are more impacted by life stress than others.

\footnotetext{
${ }^{2}$ This approach, it should be noted, is not advised, as individualism and collectivism are more properly conceptualized as two continues value orientations rather then separate ends of a single continuum (Tamis-LeMonda et al. 2008)
} 
Despite the prevalence and apparent appeal of the candidate gene GxE designs, they involve several major limitations. First, there is ongoing debate about the replicability of the findings. For example, Caspi and colleagues' (2003) study of 5-HTT and depression has been subject to numerous replications and meta-analyses that have left the verisimilitude of the finding unresolved. (e.g., Clarke, Flint, Attwood, \& Munafò, 2010; Risch et al., 2009). Similarly, a major challenge to interpreting this line of research is that, like many areas of psychology, it likely suffers from extreme publication bias (Ferguson \& Heene, 2012). Not finding that a genetic polymorphism moderates a psychological association may be very difficult to publish-especially if it has not previously been identified in the literature. Moreover, the candidate gene approach isolates a single genetic variant as being responsible for the observed psychological outcomes, when in nearly all instances multiple genes operate in conjunction to contribute to such a result (e.g., the multifactorial polygenic model; Gottesman \& Shields, 1982). Finally, analyses of candidate genes require that researchers identify and develop hypotheses about that specific gene, leaving a high likelihood of overlooking other important genetic variants (Hirschhorn \& Daly, 2005). For these reasons and more, some researchers in behavior genetics have increasingly made use of genetic-wide association studies (GWAS), which involves genotyping a large portion of the genome using very large samples $(>100,000)$ to identify common genetic variants (Hirschhorn \& Daly, 2005; but see Visscher, Brown, McCarthy, \& Yang , 2012, regarding some criticisms of the GWAS approach).

When taking these developments into consideration, consumers of cultural genetics research should be skeptical of existing genetic studies. It is critical to investigate the replicability of the association and properly assess the potential of publication bias toward statistically significant associations before taking such findings seriously. As discussed in more detail below, these cautions are not limited to research on cultural genetics, but given the historical context and interpretive affordances of this work, extra care may be called for.

The field of cultural neuroscience has enjoyed tremendous growth in recent years (Kim \& Sasaki, 2014), riding the broader wave of neuroscience perspectives that are permeating all areas of psychology (Schwartz et al., 2016). In social cognitive neuroscience, however, arguably the biggest threat to reproducibility is under-powered studies (Yarkoni, 2009). In part because of the resources involved (time and cost), social neuroscience studies tend to have very small samples. Conventional wisdom held that it was impressive to detect an effect with a small sample, suggesting that the effect is "large." One of the most important revelations in recent years is that rather than detecting an effect in spite of a small sample, it is much more likely that the effect was detected because of the small sample. The unreliability associated with the small sample, the bias introduced with questionable research practices (e.g., optional stopping in data collection, selective use of covariates), and the analytic procedures that inflate Type 1 errors work together to seriously question the reproducibility of the original findings (John et al., 2012; Simmons, Nelson, \& Simonsohn, 2011). 
Again, these issues dovetail with prior assertions that we use extra care in our theory and conceptualization when doing work at the interface of culture and biology. Many studies rely on very small samples-much too small-and results from such studies should be at best interpreted with extreme skepticism and at worst disregarded altogether. Finally, it is important to note that behavioral neuroscience researchers are working on developing solutions to the problem of small samples due to resource constraints (see Mar, Spreng, \& DeYoung, 2013, for an excellent example).

\section{Be especially attentive to effect sizes versus p-values}

By now it seems so redundant as to be trite, but it imperative that researchers put stronger interpretive weight on the observed effect sizes to understand the nature of any effect or association, rather than the binary interpretive framework enabled by $p$-values (at least within the context of null hypothesis significance testing). Effect sizes gives greater interpretive information to the strength of the association, rather than the mere presence of an association afforded by $p$-values (Cumming, 2013). In cross-national, cross-cultural, or race-comparative designs, this is especially critical because "statistically significant" differences between groups can be interpreted as "completely non-overlapping." Unfortunately, researchers will, at times provide interpretations that facilitate this way of thinking. Matsumoto, Grissom, and Dinnel's (2001) analysis of effect sizes in cultural research, which they called "cultural effect sizes," poignantly illustrated how the lack of effect size reporting can lead to faulty interpretations. And yet, despite such pleas, some researchers continue to omit effect sizes in their reports (e.g., Kitayama et al., 2015). Fortunately, effect sizes can be calculated ex post facto provided that sufficient information is included in the report: Cohen's $d$ and Pearson's $r$ can be calculated from the $t$-statistic and associated degrees of freedom $(d f)$. Calculation of effect sizes for the Kitayama et al. (2015) study indicates that they are quite small (for simple effects all $d s<.14$ and all $r$ s $<$ .09). These data are not consistent with their conclusion (effect sizes added by us) that "this pattern was quite robust for the expressive facet of anger [ $d s=.13-.15, r s=.06-.08]$, but weak for anger suppression $[d s=.06-.11, r s=.03-.06]$ and negligible for trait anger and anger control." (p. 216). To be clear, we are certainly not picking on this one paper, as the lack of reporting of effect sizes is widespread in cultural psychology, both biological and otherwise (e.g., Mathur, Harada, \& Chiao, 2012; Meisel, Ning, Campbell, \& Goodie, 2015). This practice must stop.

\section{Be skeptical of "established" measures of culture}

Another major issue in this line of research is the conceptualization and measurement of culture itself, a point that has been made by researchers in cultural and biological psychology (Caspi, Hariri, Holmes, Uher, \& Moffitt, 2010; Causadias, 2013; Matsumoto, 1999). The Hofstede (1980) index of individualism-collectivism is arguably the most widely recognized and used measure of cultural values. We have found the few researchers actually know how the Hofstede indexes were generated; this despite their ubiquity in the field. The original work was based on pre-existing data collected from over 100,000 employees of the large multi-national corporation International Business Machines (IBM) from 66 countries between 1968-1973. This brief description should raise 
several red flags and causes for concern. Moreover, despite the large sample, the sample sizes were not evenly distributed across the different countries (e.g., only 107 respondents in Pakistan). These were the data that were used to generate the index scores that are so widely used and taken as fact in some cultural-biological research (e.g., Chiao \& Blizinksy, 2010; Fincher, Thornhill, Murray, \& Schaller, 2008). We recommend McSweeney's (2002) critical review of the Hofstede indexes as required reading for any producers or consumers of cultural research, as it highlights a number of threats to the validity of a large body of research. Moreover, Hofstede's approach treats individualism-collectivism as a single continuum and static aspect of culture (Chiao \& Blizinksy, 2010; Fincher et al., 2008). Tamis -Lemonda et al.'s (2008) explication of a "dynamic" way to implement these constructs as contextualized processes linked to developmental goals is also required reading. In short, studying cultural processes is messy, and researchers should be highly skeptical of overly parsimonious approaches.

\section{These issues are not limited to culture and biology-but they are heightened}

Many of the issues raised in this chapter are, of course, not limited to culture and biology research. Issues of group definition and the need for examining underlying psychological process are just as relevant to cultural psychology on its own as they are to culture and biology research (see Helms et al., 2005; Matsumoto, 1999; Syed \& Mitchell, 2013). Similar issues are at play for research on gender and biology (Fine \& Fidler, 2014; Rippon, Jordan-Young, Kaiser, \& Fine, 2014) and for educational neuroscience (Bowers, 2016). One of the reasons that we highlight group conceptualization in this chapter is that, in the context of biological processes, the stakes are much higher. Evidence for biological processes can be interpreted as though the evidence is natural and immutable (Gould \& Heine, 2012). At the same time, the current zeitgeist of valuing biological processes in psychological research means that cultural work that includes a biological component may have a greater chance of receiving grant funding and getting published in high-visibility journals (Schwartz et al., 2016). This confluence of factors suggests that great care must be taken with conceptualization issues when doing research on culture and biology.

\section{Check assumptions, break barriers, and seek collaboration}

Conducting rigorous research on culture and biology requires expertise in both cultural and biological processes. This is a relatively rare, although not impossible, combination of expertise for an individual investigator, and there are few training programs that would adequately prepare researchers to go it alone. A fruitful path forward is to develop collaborations among researchers with differing perspectives. One barrier to doing this is simply getting these researchers in the same room. Psychology is such a fractured field, with sub-disciplines effectively operating as separate disciplines. Moreover, there needs to be greater understanding of the fact that many researchers may be interested in integrating cultural and biological perspectives, but assumptions about the interests of other researchers get in the way. In conclusion, we are all interested in human psychological functioning, and all levels of human functioning are linked to some degree, so we should pursue collaborations that can expand our understandings. 


\section{Conclusions and Future Directions}

We conclude with a cautionary tale. Increasingly, cultural psychologists are looking to move beyond the traditional focus on understanding variation in self, identity, and corresponding outcomes, and towards "larger" perspectives that signal evolutionary or otherwise biological significance. In 2014, a study published in Science linking selfconstruals to agricultural practices received quite a bit of media and scholarly attention (Talhelm, et al., 2014). The authors argued that the labor and cooperation required for rice farming leads to greater levels of interdependent self-construals, compared to wheat farming, which can be carried out relatively autonomously and is thus associated with greater independent self-construals. This move is consistent with other large-scale theories, namely the modernization hypothesis (Inglehart \& Baker, 2000) and the pathogen prevalence theory (Fincher et al., 2008), that seek to understand population-level causes for cultural variation in psychological processes. In general, this is a very good thing for the field, and if you read the Talhelm and collegeues' paper, it appears rather convincing.

Despite the appeal and apparent rigor of Talhelm and colleagues' (2014) study, several published critiques very quickly surfaced, focusing on a range of conceptual and methodological issues - some of which are quite substantial (Hu \& Yuan, 2015; Roberts, 2015; Ruan, Xie, \& Zhang, 2014). Whether or not rice and wheat production are related to psychological phenomenon remains an open question-there are simply not enough available data to draw conclusions with any certainty. It is worth reading these articles, and the others on this topic, as there are many general lessons to learn from them. One lesson in particular serves well as a parting thought: As we all seek to expand the scope and significance of our research, including greater linkage between cultural and biological processes, so too must we be careful and measured in our studies and conclusions, and how we disseminate them. In other words, by all means let us integrate cultural and biological perspectives when understanding psychological phenomena, but let us also demonstrate the appropriate caution when doing so. 


\section{References}

Anastasi, A. (1937). Differential psychology. New York: Macmillan.

Beach, S. R., Brody, G. H., Lei, M. K., Kim, S., Cui, J., \& Philibert, R. A. (2014). Is serotonin transporter genotype associated with epigenetic susceptibility or vulnerability? Examination of the impact of socioeconomic status risk on African American youth. Development and Psychopathology, 26(2), 289-304. doi: $10.1017 / \mathrm{S} 0954579413000990$

Bhopal, R. (2004). Glossary of terms relating to ethnicity and race: For reflection and debate. Journal of Epidemiology and Community Health, 58(6), 441-445. doi: 10.1136/jech.2003.013466

Bonham, V. L., Warshauer-Baker, E., \& Collins, F. S. (2005). Race and ethnicity in the genome era: The complexity of the constructs. American Psychologist, 60(1), 9. doi: 10.1037/0003-066X.60.1.9

Bowers, J. S. (2016). The practical and principled problems with educational neuroscience. Psychological Review. Online first. doi: 10.1037/rev0000025

Bruner, J. (1990). Culture and human development: A new look. Human Development, 33(6), 344-355. doi: $10.1159 / 000276535$

Cain, D. P., \& Vanderwolf, C. H. (1990). A critique of Rushton on race, brain size and intelligence. Personality and Individual Differences, 11(8), 777-784. doi: 10.1016/01918869(90)90185-T

Caspi, A., Sugden, K., Moffitt, T. E., Taylor, A., Craig, I. W., Harrington, H., ... \& Poulton, R. (2003). Influence of life stress on depression: moderation by a polymorphism in the 5HTT gene. Science, 301(5631), 386-389. doi: 10.1126/science.1083968

Caspi, A., Hariri, A. R., Holmes, A., Uher, R., \& Moffitt, T. E. (2010). Genetic sensitivity to the environment: the case of the serotonin transporter gene and its implications for studying complex diseases and traits. American Journal of Psychiatry, 167(5), 509-527. doi: 10.1176/appi.ajp.2010.09101452

Cauce, A. M., Coronado, N., \& Watson, J. (1998). Conceptual, methodological, and statistical issues in culturally competent research. In Hernandez, M. \& Isaacs, M. R. (Eds). Promoting cultural competence in children's mental health services. Systems of care for children's mental health (pp. 305-329). Baltimore, MD: Brookes Publishing.

Caulfield, T., Fullerton, S. M., Ali-Khan, S. E., Arbour, L., Burchard, E. G., Cooper, R. S., ... \& Kittles, R. (2009). Race and ancestry in biomedical research: exploring the challenges. Genome Medicine, 1(1), 1-8. doi: 10.1186/gm8

Causadias, J. M. (2013). A roadmap for the integration of culture into developmental psychopathology. Development and Psychopathology, 25(4pt2), 1375-1398. doi: $10.1017 / \mathrm{S} 0954579413000679$

Chiao, J. Y., \& Blizinsky, K. D. (2010). Culture-gene coevolution of individualism-collectivism and the serotonin transporter gene. Proceedings of the Royal Society of London B: Biological Sciences, 277(1681), 529-537. doi:10.1098/rspb.2009.1650

Chiao, J. Y., Harada, T., Komeda, H., Li, Z., Mano, Y., Saito, D., ... \& Iidaka, T. (2009). Neural basis of individualistic and collectivistic views of self. Human Brain Mapping, 30(9), 2813-2820. doi: 10.1098/rspb.2009.1650 
Clarke, H., Flint, J., Attwood, A. S., \& Munafo, M. R. (2010). Association of the 5-HTTLPR genotype and unipolar depression: a meta-analysis. Psychological Medicine, 40(11), 1767-1778. doi: $10.1017 / \mathrm{S} 0033291710000516$

Cohen, A. B. (2009). Many forms of culture. American Psychologist, 64(3), 194-204. doi: $10.1037 / \mathrm{a} 0015308$

Cokley, K. (2007). Critical issues in the measurement of ethnic and racial identity: A referendum on the state of the field. Journal of Counseling Psychology, 54(3), 224-234. doi: 10.1037/0022-0167.54.3.224

Cooper, C. R. (2011). Bridging multiple worlds: Cultures, identities, and pathways to college. New York: Oxford University Press. doi: 10.1093/acprof:oso/9780195080209.001.0001

Cumming G. (2013). The new statistics: Why and how. Psychological Science, 25, 7-29. doi: $10.1177 / 0956797613504966$

Duncan, L. E., Pollastri, A. R., \& Smoller, J. W. (2014). Mind the gap: Why many geneticists and psychological scientists have discrepant views about gene-environment interaction $(\mathrm{G} \times \mathrm{E})$ research. American Psychologist, 69(3), 249-268. doi: $10.1037 / \mathrm{a} 0036320$

Durrheim, K., \& Dixon, J. (2010). Racial contact and change in South Africa. Journal of Social Issues, 66(2), 273-288. doi: 10.1111/j.1540-4560.2010.01645.x

Ferguson, C. J., \& Heene, M. (2012). A vast graveyard of undead theories: Publication bias and psychological science's aversion to the null. Perspectives on Psychological Science, 7(6), 555-561. doi: 10.1177/1745691612459059

Fincher, C. L., Thornhill, R., Murray, D. R., \& Schaller, M. (2008). Pathogen prevalence predicts human cross-cultural variability in individualism/collectivism. Proceedings of the Royal Society of London B: Biological Sciences, 275(1640), 1279-1285. doi: 10.1098/rspb.2008.0094

Fine, C., \& Fidler, F. (2015). Sex and power: Why sex/gender neuroscience should motivate statistical reform. In J. Clausen \& N. Levy (Eds.), Handbook of neuroethics (pp. 14471462). Springer: Netherlands. doi: 10.1007/978-94-007-4707-4 156

Gaines Jr, S. O., Bunce, D., Robertson, T., Barlow Wright with Yoeri Goossens, Heer, D., Lidder, A., ... \& Minhas, S. (2010). Evaluating the psychometric properties of the Multigroup Ethnic Identity Measure (MEIM) within the United Kingdom. Identity, 10(1), 1-19. doi: $10.1080 / 15283481003676176$

García Coll, C., Lamberty, G., Jenkins, R., McAdoo, H. P., Crnic, K., Wasik, B. H., \& Garcia, H. V. (1996). An integrative model for the study of developmental competencies in minority children. Child Development, 67, 1891-1914. doi: $\underline{10.2307 / 1131600}$

García Coll, C., Akerman, A., \& Cicchetti, D. (2000). Cultural influences on developmental processes and outcomes: Implications for the study of development and psychopathology. Development and Psychopathology, 12(3), 333-356. doi: $10.1017 / \mathrm{S} 0954579400003059$

Gjerde, P. F. (2004). Culture, power, and experience: Toward a person-centered cultural psychology. Human Development, 47(3), 138-157. dio: 10.1159/000077987

Gottesman, I. I., \& Shields, J. (1982). Schizophrenia. CUP Archive.

Gottfredson, L. S. (1997). Mainstream science on intelligence: An editorial with 52 signatories, history, and bibliography. Intelligence, 24(1), 13-23. doi: 10.1016/S01602896(97)90011-8

Gould, W. A., \& Heine, S. J. (2012). Implicit essentialism: genetic concepts are implicitly associated with fate concepts. PloS One, 7(6), e38176. doi:10.1371/journal.pone.0038176 
Graves, J. L. (2001). The emperor's new clothes: Biological theories of race at the millennium. New Jersey: Rutgers University Press.

Gyberg, F., Syed, M., Frisén, A., Wängqvist, M. \& Svensson, Y. (2016). “Another kind of Swede": Ethnic identity in contemporary Sweden. Manuscript submitted for publication.

Hammack, P. L. (2008). Narrative and the cultural psychology of identity. Personality and Social Psychology Review, 12, 222-247. doi: 10.1177/1088868308316892

Han, S., Northoff, G., Vogeley, K., Wexler, B. E., Kitayama, S., \& Varnum, M. E. (2013). A cultural neuroscience approach to the biosocial nature of the human brain. Annual Review of Psychology, 64, 335-359. doi: 10.1146/annurev-psych-071112-054629

Harre, R. (2015). The person as the nexus of patterns of discursive practices. Culture \& Psychology, 21(4), 492-504. doi: 10.1177/1354067X15615808

Helms, J. E., Jernigan, M., \& Mascher, J. (2005). The meaning of race in psychology and how to change it: A methodological perspective. American Psychologist, 60(1), 27. doi: 10.1037/0003-066X.60.1.27

Herrnstein, R., \& Murray, C. (1994). The bell curve. New York: Free Press.

Hirschhorn, J. N., \& Daly, M. J. (2005). Genome-wide association studies for common diseases and complex traits. Nature Reviews Genetics, 6(2), 95-108. doi: 10.1038/nrg1521

Hochschild, J.L. (2005). Looking ahead: Racial trends in the United States. Daedalus, 134(1), 70-81. doi: $10.1162 / 0011526053124343$

Hofstede, G. (1980). Culture's consequences: International differences in work-related values. Beverly Hills, CA: Sage.

Hu, S., \& Yuan, Z. (2015). Commentary: "Large-scale psychological differences within China explained by rice vs. wheat agriculture". Frontiers in Psychology. 6:489. doi: 10.3389/fpsyg.2015.00489

Humes K., Jones, N., Ramirez, R. (2011). Overview of race and Hispanic origin. 2010 Census Briefs. Retrieved from http://www.census.gov/prod/cen2010/briefs/c2010br-02.pdf.

Inglehart, R., \& Baker, W. E. (2000). Modernization, cultural change, and the persistence of traditional values. American Sociological Review, 65(1), 19-51. doi: $\underline{10.2307 / 2657288}$

John, L. K., Loewenstein, G., \& Prelec, D. (2012). Measuring the prevalence of questionable research practices with incentives for truth telling. Psychological Science, 23, 524-532. doi: $10.1177 / 0956797611430953$

Kim, H. S., \& Sasaki, J. Y. (2014). Cultural neuroscience: Biology of the mind in cultural contexts. Annual Review of Psychology, 65, 487-514. doi: 10.1146/annurev-psych010213-115040

Kitayama, S., \& Cohen, D. (Eds.). (2010). Handbook of cultural psychology. Guilford Press.

Kitayama, S., Park, J., Boylan, J. M., Miyamoto, Y., Levine, C. S., Markus, H. R., ... \& Ryff, C. D. (2015). Expression of anger and ill health in two cultures: An examination of inflammation and cardiovascular risk. Psychological Science, 26(2), 211-220. doi: $10.1177 / 0956797614561268$

Leont'ev, A. N. (1978). Activity, consciousness, and personality. Englewood Cliffs, NJ: Prentice-Hall.

Lipka, M. (2015). Muslim and Islam: Key findings in the U.S. and around the world. Pew Research Center. Retrieved from http://www.pewresearch.org/facttank/2015/12/07/muslims-and-islam-key-findings-in-the-u-s-and-around-the-world/.

Lipsitz, G. (1998). The possessive investment of Whiteness. Philadelphia: Temple University Press. 
Mar, R. A., Spreng, R. N., \& DeYoung, C. G. (2013). How to produce personality neuroscience research with high statistical power and low additional cost. Cognitive, Affective, and Behavioral Neuroscience, 13, 674-685. doi: 10.3758/s13415-013-0202-6

Markus, H. R., \& Kitayama, S. (1991). Culture and the self: Implications for cognition, emotion, and motivation. Psychological Review, 98(2), 224. doi: 10.1037/0033-295X.98.2.224

Mathur, V. A., Harada, T., \& Chiao, J. Y. (2012). Racial identification modulates default network activity for same and other races. Human Brain Mapping, 33(8), 1883-1893. doi: $10.1002 / \mathrm{hbm} .21330$

Matsumoto, D. (1999). Culture and self: An empirical assessment of Markus and Kitayama's theory of independent and interdependent self-construals. Asian Journal of Social Psychology, 2(3), 289-310. doi: 10.1111/1467-839X.00042

Matsumoto, D. (2003). Cross-cultural research. In S. Davis (Ed.), The handbook of research methods in experimental psychology. Oxford, UK: Blackwell. doi: 10.1002/9780470756973.ch9

Matsumoto, D., Grissom, R. J., \& Dinnel, D. L. (2001). Do between-culture differences really mean that people are different? A look at some measures of cultural effect size. Journal of Cross-Cultural Psychology, 32(4), 478-490. doi: $10.1177 / 0022022101032004007$

McLean, K. C., \& Syed., M. (in press). Personal, master, and alternative narratives: An integrative framework for understanding identity development in context. Human Development. doi: $10.1159 / 000445817$

McSweeney, B. (2002). Hofstede's model of national cultural differences and their consequences: A triumph of faith-a failure of analysis. Human Relations, 55(1), 89-118. doi: $10.1177 / 0018726702551004$

Meer, N., \& Modood, T. (2009). The multicultural state we're in: Muslims, multicultural and the civic rebalancing of British multiculturalism. Political Studies, 57(3), 473-497. doi: 10.1111/j.1467-9248.2008.00745.x

Meisel, M. K., Ning, H., Campbell, W. K., \& Goodie, A. S. (2015). Narcissism, overconfidence, and risk taking in US and Chinese student samples. Journal of Cross-Cultural Psychology, 47(3) 385-400. doi: 10.1177/0022022115621968

Mrazek, A. J., Harada, T., \& Chiao, J. Y. (2015). Cultural neuroscience of identity development. In K. C. McLean and M. Syed (Eds.), The Oxford Handbook of Identity Development (423-436). New York: Oxford. doi: 10.1093/oxfordhb/9780199936564.013.22

Neblett, E. W., \& Roberts, S. O. (2013). Racial identity and autonomic responses to racial discrimination. Psychophysiology, 50(10), 943-953. doi: 10.1111/psyp.12087

Neisser, U., Boodoo, G., Bouchard Jr, T. J., Boykin, A. W., Brody, N., Ceci, S. J., ... \& Urbina, S. (1996). Intelligence: knowns and unknowns. American Psychologist, 51(2), 77. doi: 10.1037/0003-066X.51.2.77

Obasi, E. M., Shirtcliff, E. A., Brody, G. H., MacKillop, J., Pittman, D. M., Cavanagh, L., \& Philibert, R. A. (2015). The relationship between alcohol consumption, perceived stress, and CRHR1 genotype on the hypothalamic-pituitary-adrenal axis in rural African Americans. Frontiers in Psychology, 6. doi: 10.3389/fpsyg.2015.00832

Open Science Collaboration. (2015). Estimating the reproducibility of psychological science. Science, 349(6251), aac4716. doi: 10.1126/science.aac4716

Oyserman, D., Coon, H. M., \& Kemmelmeier, M. (2002). Rethinking individualism and collectivism: evaluation of theoretical assumptions and meta-analyses. Psychological Bulletin, 128(1), 3. doi: 10.1037/0033-2909.128.1.3 
Rees, D. C., Williams, T. N., \& Gladwin, M. T. (2010). Sickle-cell disease. The Lancet, 376(9757), 2018-2031. doi: 10.1016/S0140-6736(10)61029-X

Rippon, G., Jordan-Young, R., Fine, C., \& Kaiser, A. (2014). Recommendations for sex/gender neuroimaging research: Key principles and implications for research design, analysis and interpretation. Frontiers in Human Neuroscience, 8, 1-13. doi: 10.3389/fnhum.2014.00650

Risch, N., Burchard, E., Ziv, E., \& Tang, H. (2002). Categorization of humans in biomedical research: genes, race and disease. Genome Biology, 3(7), 1-12. doi: 10.1186/gb-2002-3-7comment 2007

Risch, N., Herrell, R., Lehner, T., Liang, K. Y., Eaves, L., Hoh, J., ... \& Merikangas, K. R. (2009). Interaction between the serotonin transporter gene (5-HTTLPR), stressful life events, and risk of depression: a meta-analysis. JAMA, 301(23), 2462-2471. doi: 10.1001/jama.2009.878

Roberts, S. G. (2015) Commentary: Large-scale psychological differences within China explained by rice vs. wheat agriculture. Frontiers in Psychology, 6, 950. doi: 10.3389/fpsyg. 2015.00950

Rogoff, B. (2003). The cultural nature of human development. New York: Oxford University Press.

Ruan J., Xie Z., Zhang X. (2014). Does rice farming shape individualism and innovation? A response to Talhelm et al. (2014). The International Food Policy Research Institute (IFPRI) Discussion Paper.

Rushton, J. P., \& Jensen, A. R. (2005). Thirty years of research on race differences in cognitive ability. Psychology, Public Policy, and Law, 11(2), 235-294. doi: 10.1037/1076$\underline{8971.11 .2 .235}$

Schwartz, S. J., Lilienfeld, S. O., Meca, A., \& Sauvigné, K. C. (2016). The role of neuroscience within psychology: A call for inclusiveness over exclusiveness. The American Psychologist, 71(1), 52-70. doi: 10.1037/a0039678

Segall, M. H., Lonner, W. J., \& Berry, J. W. (1998). Cross-cultural psychology as a scholarly discipline: On the flowering of culture in behavioral research. American Psychologist, 53(10), 1101. doi: 10.1037/0003-066X.53.10.1101

Seginer, R., \& Mahajna, S. (2004). How the future orientation of traditional Israeli Palestinian girls links beliefs about women's roles and academic achievement. Psychology of Women Quarterly, 28(2), 122-135. doi: 10.1111/j.1471-6402.2004.00129.x

Serre, D., \& Pääbo, S. (2004). Evidence for gradients of human genetic diversity within and among continents. Genome Research, 14(9), 1679-1685. doi: 10.1101/gr.2529604

Shweder, R. A. (2000). The psychology of practice and the practice of the three psychologies. Asian Journal of Social Psychology, 3(3), 207-222. doi: 10.1111/1467-839X.00065

Simmons, J. P., Nelson, L. D., \& Simonsohn, U. (2011). False-positive psychology undisclosed flexibility in data collection and analysis allows presenting anything as significant. Psychological Science, 22(11) 1359-1366. doi: $10.1177 / 0956797611417632$

Smedley, A., \& Smedley, B. D. (2005). Race as biology is fiction, racism as a social problem is real: Anthropological and historical perspectives on the social construction of race. American Psychologist, 60(1), 16-26. doi: 10.1037/0003-066X.60.1.16

Snowden, L. R. (2012). Health and mental health policies' role in better understanding and closing African American-White American disparities in treatment access and quality of care. American Psychologist, 67(7), 524-531. doi: 10.1037/a0030054 
Solis, J. (2003). Re-thinking illegality as a violence against, not by Mexican immigrants, children, and youth. Journal of Social Issues, 59(1), 15-31. doi: 10.1111/1540$\underline{4560.00002}$

Syed, M., \& Mitchell, L. L. (2013). Race, Ethnicity, and Emerging Adulthood Retrospect and Prospects. Emerging Adulthood, 1(2), 83-95. doi: 10.1177/2167696813480503

Takano, Y., \& Osaka, E. (1999). An unsupported common view: Comparing Japan and the US on individualism/collectivism. Asian Journal of Social Psychology, 2(3), 311-341. doi: $\underline{10.1111 / 1467-839 X .00043}$

Talhelm, T., Zhang, X., Oishi, S., Shimin, C., Duan, D., Lan, X., \& Kitayama, S. (2014). Largescale psychological differences within China explained by rice versus wheat agriculture. Science, 344(6184), 603-608. doi: 10.1126/science.1246850

Tamis-LeMonda, C. S., Way, N., Hughes, D., Yoshikawa, H., Kalman, R. K., \& Niwa, E. Y. (2008). Parents' goals for children: The dynamic coexistence of individualism and collectivism in cultures and individuals. Social Development, 17(1), 183-209. doi: 10.1111/j.1467-9507.2007.00419.x

Teo, T. (2009). Psychology without Caucasians. Canadian Psychology/Psychologie canadienne, 50(2), 91. doi: $10.1037 / \mathrm{a} 0014393$

Turkheimer, E., Haley, A., Waldron, M., D'Onofrio, B., \& Gottesman, I. I. (2003). Socioeconomic status modifies heritability of IQ in young children. Psychological Science, 14(6), 623-628. doi: 10.1046/j.0956-7976.2003.psci_1475.x

Umaña-Taylor, A. J., Quintana, S. M., Lee, R. M., Cross, W. E., Rivas-Drake, D., Schwartz, S. J., ... \& Seaton, E. (2014). Ethnic and racial identity during adolescence and into young adulthood: An integrated conceptualization. Child Development, 85(1), 21-39. doi: $\underline{10.1111 / \mathrm{cdev} .12196}$

Verkuyten, M. (2005). Ethnic group identification and group evaluation among minority and majority groups: testing the multiculturalism hypothesis. Journal of Personality and Social Psychology, 88(1), 121. doi: 10.1037/0022-3514.88.1.121

Visscher, P. M., Brown, M. A., McCarthy, M. I., \& Yang, J. (2012). Five years of GWAS discovery. The American Journal of Human Genetics, 90(1), 7-24. doi: 10.1016/j.ajhg.2011.11.029

Vygotsky, L. S. (1978). Mind in society. Cambridge, MA: Harvard University Press.

Yarkoni, T. (2009). Big correlations in little studies: Inflated fMRI correlations reflect low statistical power - Commentary on Vul et al.(2009). Perspectives on Psychological Science, 4(3), 294-298. doi: 10.1111/j.1745-6924.2009.01127.x 


\section{Author Bios}

Moin Syed is an Associate Professor in the Department of Psychology at the University of Minnesota. His research interests lie broadly in how adolescents and young adults from diverse ethnic, racial, and cultural backgrounds weave together their multiple identities to lead healthy, productive, and purposeful lives.

Ummul-Kiram Kathawalla is a PhD student and National Science Foundation Graduate Research Fellow in the Department of Psychology at the University of Minnesota. Her research interests focus on understanding how various interpersonal, societal and personal factors influence minority identity development. She is particularly interested in how identity formation contributes to the development and persistence of psychological conditions and physiological well-being. 